\title{
Cateterismo intermitente limpo em crianças com bexiga urinária neurogênica: o cuidado do familiar no domicílio
}

\section{Clean intermittent catheterization in children with neurogenic urinary bladder: home care by relatives}

\section{Cateterismo intermitente limpio en niños con vejiga urinaria neurogénica: el cuidado de la familia en casa}

\author{
Suzana Antonio ; Sandra Teixeira de Araújo Pacheco ${ }^{I I}$; Márcia Pereira Fernandes Gomes ${ }^{\text {III; }}$ \\ Adriana Teixeira Reis ${ }^{I V}$; Benedita Maria Rêgo Deusdará Rodrigues ${ }^{V}$; Simone Muniz de Souza ${ }^{V I}$
}

\begin{abstract}
RESUMO: A pesquisa buscou conhecer os cuidados realizados pelo familiar à criança portadora de bexiga neurogênica que necessita de cateterismo vesical intermitente limpo, no domicilio. Trata-se de um estudo qualitativo, realizado em ambulatório de pediatria de um hospital universitário, localizado na cidade do Rio de Janeiro. A coleta dos dados deu-se com 12 familiares através de entrevistas semiestruturadas, no período de janeiro a julho de 2014. Para o tratamento dos dados foi utilizada a análise de conteúdo de Bardin, dando origem a três categorias analíticas: Organizando o ambiente e a criança para o cateterismo; Preparo das mãos para a realização do cateterismo; A realização da técnica pelo familiar. Conclui-se que o cateterismo é realizado conforme a técnica descrita em literatura, mas existem determinados familiares que realizam inadequadamente certos passos da técnica. Sugere-se a realização de protocolos de orientação aos familiares para uniformização de condutas e grupos de apoio aos mesmos. Palavras-Chave: Bexiga urinária neurogênica; cuidado da criança; família; cateterismo uretral intermitente.
\end{abstract}

\begin{abstract}
This qualitative study to examine care provided by family members to children with neurogenic bladder needing clean intermittent catheterization at home was conducted at a pediatric outpatient department of a university hospital in Rio de Janeiro City. Data was collected by semi-structured interviews of 12 family members, between January and July 2014 . Data were examined using Bardin content analysis, resulting in three categories: organizing the environment and the child for the catheterization; preparing hands to perform the catheterization; and the technique performed by the family member. It was concluded that catheterization is performed according to the technique described in the literature, but certain family members perform some steps of the technique inappropriately. We suggest producing guidance protocols for family members to standardize conduct, and holding support groups for them.

Keywords: Neurogenic urinary bladder; child care; family; intermittent urethral catheterization.
\end{abstract}

RESUMEN: La investigación tuvo como objetivo conocer la atención realizada por la familia al niño portador de vejiga neurogénica que necesita cateterismo vesical intermitente limpio en su residencia. Se trata de un estudio cualitativo, realizado en una clínica pediátrica ambulatoria de un hospital universitario ubicado en la ciudad de Río de Janeiro. La recolección de datos se llevó a cabo con 12 familias a través de entrevistas semiestructuradas, en el período de enero a julio de 2014. Para estudio de datos se utilizó el análisis de contenido de Bardin, dando lugar a tres categorías de análisis: La organización del ambiente y del niño al cateterismo; Preparación de las manos para la realización del cateterismo; La realización de la técnica por la familia. Se concluye que el cateterismo se realiza según la técnica descrita en la literatura, pero hay algunos miembros de la familia que realizan inadecuadamente algunos pasos de la técnica. Se sugiere la realización de protocolos de orientación a los familiares con vistas a uniformizar las conductas y grupos de apoyo a los mismos.

Palabras Clave: Vejiga urinaria neurogénica; cuidado del niño; família; cateterismo uretral intermitente.

\section{INTRODUÇÃO}

A bexiga urinária neurogênica é uma disfunção vesicoesfincteriana de origem neurológica, que pode acarretar lesão renal progressiva se o cateterismo inter- mitente limpo (CIL) não for realizado adequadamente e regularmente. Esse comprometimento nervoso acarretador de toda disfunção, pode ser congênito ou ad-

\footnotetext{
IEnfermeira Especialista em Pediatria pela Universidade do Estado do Rio de Janeiro. Mestranda em Enfermagem pela Faculdade de Enfermagem da Universidade do Estado do Rio de Janeiro.E-mail: suzananv@hotmail.com

IIDoutora em Enfermagem pela Escola de Enfermagem Anna Nery. Professora Adjunta do Departamento de Enfermagem Materno-Infantil da Faculdade de Enfermagem da Universidade Estado do Rio de Janeiro. Brasil. E-mail: stapacheco@yahoo.com.br

IIIMestre em Enfermagem. Enfermeira do Ambulatório de Pediatria do Hospital Universitário Pedro Ernesto. Rio de Janeiro, Brasil. E-mail: marciapfg@hotmail.com ${ }^{I V}$ Doutora em Enfermagem. Professora Adjunta do Departamento de Enfermagem Materno Infantil da Faculdade de Enfermagem da Universidade do Estado do Rio de Janeiro. Brasil. E-mail: drireis@iff.fiocruz.br

voutora em Enfermagem. Professora Titular do Departamento de Enfermagem Materno-Infantil, integrante do Corpo Docente da Graduação e PósGraduação da Faculdade de Enfermagem da Universidade do Estado do Rio de Janeiro. Brasil. E-mail: benedeusdara@gmail.com

${ }^{\mathrm{V}}$ Especialista em Enfermagem Pediátrica. Mestranda em Enfermagem pela Faculdade de Enfermagem da Universidade do Estado do Rio de Janeiro. Brasil.

E-mail: simonsms@ig.com.br
} 
quirido. Dentre as causas de lesão congênita, podemos destacar a mielodisplasia como a mais frequente e os traumatismos e tumores de medula espinhal como causas de lesão adquirida ${ }^{1,2}$.

A mielodisplasia é comumente encontrada na meningocele e mielomeningocele. As crianças possuem formas de aparência clínica variáveis, mas geralmente apresentam incontinência urinária como sintoma predominante. As infecções do trato urinário também são frequentes, podendo atingir os rins, ocasionando pielonefrites. Além das observações físicas, é importante a investigação do aspecto social e emocional, já que essas crianças passam por muitas internações hospitalares, retornos ambulatoriais e cuidados especiais que lhe estabelecem condições de vida diferentes, podendo afetar sua vida social e integração na escola, gerando, possivelmente, alteração em toda rotina e relacionamento familiar².

Todo este contexto da criança com bexiga urinária neurogênica, as inclui como membros de um novo grupo infantil emergente na sociedade, conhecido internacionalmente, por Children with Special Health CareNeeds (CSHCN) e no Brasil como Crianças com Necessidades Especiais de Saúde (CRIANES), que ressaltam a vulnerabilidade social e a ausência de políticas públicas específicas para esse público ${ }^{3}$.

Muitas de suas necessidades são heranças do processo terapêutico reparador de sua condição de saúde/ doença. As crianças com bexiga urinária neurogênica são dependentes de cuidados que exigem a adaptação da família e da criança e o aprendizado de cuidados técnicos tais como: cateterismo vesical intermitente, administração de medicamentos de uso contínuo, dentre outros. Além disso, enfrentam dificuldades de convívio social e relacionamentos, sobrecarga física e emocional, complicações que algumas vezes necessitam de acompanhamento permanente em serviços ambulatoriais ou até mesmo hospitalizações ${ }^{4,5}$.

Apesar das necessidades especiais de saúde dessa criança, atualmente, são escassos, na literatura cientifica, estudos que abordem os cuidados dos familiares junto à mesma, quando no contexto domiciliar. $\mathrm{Na}$ assistência à saúde da criança, geralmente a enfermeira faz parte do processo de treinamento de seus familiares para a realização dos cuidados domiciliares. Diante dessa problemática, o presente estudo buscou conhecer os cuidados realizados pelo familiar à criança portadora de bexiga neurogênica, no domicilio.

\section{REVISÃO DE LITERATURA}

As crianças com bexiga neurogênica incluem-se no grupo CRIANES, devido à sua dependência de algumas tecnologias e medicamentos, destaca-se que possuem disfunção neuromuscular e dependem de modificações habituais de cuidar.
O cateter vesical é uma tecnologia utilizada continuamente por esse grupo de crianças, através do CIL, como uma das principais ferramentas no tratamento $^{6}$. Ele permite o esvaziamento periódico da bexiga, mediante a introdução de um cateter na uretra ou em um estoma continente. Esta prática tem como objetivo principal promover o esvaziamento da bexiga, evitando complicações decorrentes de sua distensão exagerada e melhorando as condições do trato urinário ${ }^{7}$.

O CIL, por ser uma técnica simples, segura e de baixo custo, tem, em geral, boa aceitação pela maior parte dos portadores de bexiga neurogênica e sua família. Porém, podem ocorrer algumas complicações se realizado de maneira incorreta, como traumatismos na uretra, estenose uretral, sangramentos, infecções do trato urinário, falsos trajetos na uretra, epididimite e, mais raramente, perfurações na bexiga ${ }^{8}$.

A recomendação para realização do cateterismo intermitente é a cada 4 ou 6 horas, de acordo com o balanço hídrico do paciente, para evitar o superestiramento da bexiga e a infecção do trato urinário. Para avaliar o volume máximo de cada esvaziamento, devese conhecer a capacidade vesical e a urodinâmica desse paciente. Ainda, é orientado à família que elabore o diário miccional e também registre qualquer sensação sistêmica incomum que ocorrer? .

Observa-se na prática o abandono do CIL ou uma inadequada técnica e, como justificativas, estão as condições financeiras na aquisição de material, a resistência da criança e a indisponibilidade de tempo do responsável para a realização do procedimento ${ }^{8}$.

\section{Metodologia}

Trata-se de uma pesquisa de abordagem qualitativa e descritiva, cujo cenário foi o ambulatório de pediatria de um hospital universitário situado, no município do Rio de Janeiro. Participaram da pesquisa, 12 familiares de crianças com bexiga urinária neurogênica que atenderam aos critérios de inclusão, ou seja, ser familiar de criança portadora de bexiga urinária neurogênica, acompanhada no ambulatório de pediatria em questão e realizar diretamente cuidados com o CIL. O projeto foi aprovado pelo Comitê de Ética em Pesquisa da referida instituição, sob número de parecer: 517.563. A coleta de dados deu-se nos meses de janeiro a julho de 2014 .

Para obtenção dos dados foi realizada uma entrevista semiestruturada. Para registro das falas dos participantes, foi utilizada a gravação em áudio, através de um celular da marca Motorola, modelo RAZR DI. $\mathrm{O}$ anonimato dos participantes foi garantido através da utilização de um pseudônimo com o nome de flor de sua preferência, e todos foram esclarecidos quanto ao sigilo das informações coletadas, bem como ao direito 
à desistência de sua participação em qualquer fase da pesquisa. Foi entregue uma cópia do Termo de Consentimento Livre e Esclarecido a cada participante após a leitura em conjunto com a pesquisadora e realizados os devidos esclarecimentos; obteve-se a anuência, por escrito, de cada participante, no citado termo. A fim de que objetivo do estudo fosse alcançado, perguntouse: Quais os cuidados que você realiza com a criança portadora de bexiga neurogênica frente ao cateterismo intermitente limpo no domicílio?

O tratamento das informações obtidas, durante a entrevista, foi alicerçado na análise de conteúdo ${ }^{10}$ na modalidade temática, o que permitiu a codificação, desdobramento, agrupamento e síntese dos depoimentos, resultando em três categorias analíticas.

\section{Resultados e Discussão}

As categorias emergentes dos discursos dos familiares são descritas a seguir.

\section{Categoria 1: Organizando o ambiente e a criança para o CIL}

A organização do espaço ambiental e dos materiais a serem utilizados são necessários ao bom desempenho na realização do cateterismo. Alguns familiares ressaltaram tais zelos como itens importantes no cuidado à criança portadora de bexiga neurogênica:

[...] deito ela na cama, boto a toalha direitinho, tenho uma maletinha [...] que tem os produtos, tudo ali arrumadinho. (Tulipa)

Preparo tudo, já deixo tudo preparado em cima da cama, num pano. (Alecrim)

As participantes mencionaram a organização do local e disponibilização dos materiais antes do procedimento sobre a cama ou uma mesa. A este respeito, recomenda-se que antes de realizar o CIL, devem-se reunir os materiais necessários (sonda estéril ou limpa, lubrificante a base de água, sabão, toalha limpa, água e um recipiente para coletar urina se necessário) ${ }^{11}$.

É fundamental que o procedimento siga uma sistematização e critérios rigorosos para a sua execução, pois a organização do local, o preparo dos materiais e a higienização da criança influenciam no sucesso da técnica. Além disso, pode-se observar a preocupação dos familiares com a higiene da criança:

Eu a lavo [a criança] com sabonete neutro em barra e água, aí seco direitinho. (Violeta)

[...] lavo com clorexidina, e soro ou então água mesmo, aí ali eu lavo as partes genitais dela. (Rosa Vermelha)

Quando as crianças que necessitam do cateterismo intermitente estão em ambiente domiciliar, preconiza-se a técnica limpa, sendo um recurso seguro para os pacientes com bexiga urinária neurogênica, comprovado por pesquisas nacionais e internacionais. A técnica consiste, além de uma rigorosa higiene das mãos, também da limpeza e do preparo da criança, sendo parte integrante da mesma, devendo ser realizada com atenção e de forma correta ${ }^{12}$.

A direção dos movimentos durante a limpeza com sabão também deve ser levada em consideração, de acordo com as seguintes narrativas:

[...] primeiro por fora, depois abaixo o prepúcio. (Margarida Rosa)

[.. aí eu pego a água e vou limpando com o algodão, molho sempre com a água e vou tirando tudo, pomada, as fezes, a urina, de cima para baixo. (Magnólia)

No sexo feminino, a higiene deve ser realizada utilizando o polegar e o indicador da mão não dominante para separar os pequenos e grandes lábios ou dobras da pele que cobre a vagina e localizar o meato uretral. Com os lábios separados, a área da uretra deve ser higienizada de frente para trás, cuidadosamente, com água e sabão neutro. Para o sexo masculino, deve-se realizar a limpeza retraindo o prepúcio, se o pênis não possui fimose, até a completa exposição da glande. Lava-se a mesma com água e sabão neutro, com movimentos circulares, a partir da extremidade ${ }^{11}$.

Dessa forma, pode-se perceber que os familiares realizam a técnica de forma organizada e com princípios técnicos, conforme preconizado na literatura ${ }^{11}$, adaptando o cuidado leigo à prática quase profissional.

\section{Categoria II: Preparo das mãos visando a realização do cateterismo}

Nesta segunda categoria, os familiares apontaram a preocupação com a higienização das mãos antes de realizar o CIL.

Lavo antes as mãos com o sabonete líquido neutro. (Margarida Rosa)

Lavo as mãos antes de tudo. E se eu, no caso, uso o trocador, tento lavar a mão, eu vou e passo o álcool nele, aí eu vou fazendo as coisas e na última etapa eu lavo a mão para pegar a sonda e fazer, mas às vezes eu já lavei a mão e esqueci a fralda, aí eu vou, desço de novo e lavo a mão. (Magnólia)

Primeiro lavar as mãos, lavo as mãos, aí depois lavo as mãos novamente, passo álcool nas mãos, álcool 70\%. (Lotus)

As mãos do familiar fazem o principal papel na realização do cateterismo. Elas são imprescindíveis e devem estar preparadas e higienizadas de maneira correta. Mesmo não sendo uma técnica estéril, o cateterismo intermitente limpo necessita de que o familiar realize com cuidado e atenção a higienização das mãos. A utilização simples de água e sabão neutro pode reduzir a população microbiana e, na maioria das vezes, interromper a cadeia de transmissão de doenças, prevenindo 
assim as infecções urinárias. As mãos devem ser lavadas, após tocar qualquer material contaminado, antes e após a realização de qualquer procedimento ${ }^{13}$.

Entretanto, verifica-se que em algumas situações, mencionam o uso de luvas durante o procedimento com as crianças:

[...] às vezes quando têm condições eu coloco a luva. Coloco a luva sem sujar. Nem sempre uso. Aqui ensinou a fazer sem a luva, mas ela estava dando muita infecção, aí quando dá, faço com a luva. (Margarida)

Cheguei a usar luva um tempo, depois parei porque a médica pediu para parar porque poderia dar alergia. (Margarida Rosa)

Luva de procedimento. A estéril só usava quando tinha que fazer algum exame ou coisa assim. (Jasmim)

A literatura não sustenta a prática do uso de luvas no CIL. A higienização das mãos dispensa o uso das mesmas, de qualquer antisséptico ou outros materiais esterilizados ${ }^{12}$. Entretanto, esses familiares podem ter recebido orientações sobre tal exigência, no contexto hospitalar, o que pode vir a justificar seu uso. Dessa forma, parecem transferir o que foi aprendido durante a hospitalização para o cuidado da criança no domicílio.

\section{Categoria III: A realização da técnica do cateterismo pelo familiar}

As falas dos familiares entrevistados apontaram o uso de lubrificante antes da introdução da sonda na criança.

Uso a pomada x, tiro um pouco do tubo, espirro um pouco, aí passo uma quantidade direto na sonda, sem encostar na sonda. (Tulipa)

Passo a pomadinha. Toda vez. Passo na borrachinha. Deixo em cima do papel, no papelzinho, que tem lá, da gaze e passo a borrachinha. (Violeta)

[...] e pego a sonda e aí enrolo a sonda, assim, na minha mão, assim, e boto, antes de botar a pomada eu jogo um pouquinho fora, e depois eu coloco na sonda. (Azaléia)

As falas apontam o uso de um mesmo tipo de pomada lubrificante, a qual também possui efeito anestésico em sua constituição. Essas falas refletem a preocupação do familiar não causar nenhum tipo de reação adversa inerente ao procedimento, tais como trauma na mucosa e dor na criança.

A maioria dos lubrificantes hidrossolúveis em gel, com anestésico, promovem anestesia rápida e profunda da mucosa e lubrificação que reduz a fricção. São caracterizados pela alta viscosidade e baixa tensão superficial, proporcionando contato íntimo e prolongado do anestésico com o tecido, produzindo anestesia eficiente de longa duração (20-30 minutos), sendo o início de ação rápido (dentro de 5 minutos, dependendo da área de aplicação) ${ }^{14}$.
Entretanto, observa-se entre as falas que um dos familiares, algumas vezes, acaba não utilizando o lubrificante no procedimento:

[...] lubrifico a sonda com a pomada X. Uso bem pouquinho, na pontinha, um pinguinho e pomada em cima da mão, e passo a pontinha da sonda. Eás vezes eu faço sem ela. (Lotus)

A orientação ao familiar sobre o uso do lubrificante evita lesões na mucosa uretral. Deve-se aplicar uma adequada quantidade de lubrificante na ponta e nos primeiros centímetros de cateter antes de introduzi-lo ${ }^{11}$.

f familiar deve ser orientado ainda sobre os possíveis efeitos adversos do uso exagerado do lubrificante com anestésico. Como para qualquer anestésico local, as reações e complicações são evitadas utilizando-se a menor dose eficaz e em crianças com idade inferior a 12 anos. Os efeitos adversos desses lubrificantes com anestésicos podem ser toxicidade sistêmica aguda e reações alérgicas ${ }^{14}$.

Para introduzir a sonda, também é necessário a visualização completa do meato urinário pelo familiar. Para isso existem manobras necessárias com peculiaridades para cada sexo. As falas seguintes apontam o modo como os familiares relataram a realização deste procedimento:

Aí introduzo (a sonda), abro bem a região genital e introduzo. (Tulipa)

\section{[...] abro a vagina e introduzo a sonda. (Margarida)}

Arregaço o peruzinho e introduzo a sonda. (Girassol)

A literatura preconiza que nos meninos se realiza a exposição da glande (se não houver fimose), expondo o prepúcio e o meato urinário, é preciso manter o pênis ereto com uma das mãos e com a outra (de preferência a dominante) inserir lentamente o cateter já lubrificado, pela uretra. Nas meninas usase o polegar e indicador da mão não dominante para separar os grandes e pequenos lábios ou dobras da pele que cobre a vagina e localizar o meato urinário. Com a mão dominante, inserir o cateter já lubrificado, de forma delicada pela uretra ${ }^{11}$.

Ressalta-se que a anatomia genital da criança, além de pequenas dimensões, apresenta estruturas delicadas que podem se confundir, principalmente no sexo feminino. Não é incomum durante a técnica, realizada por profissional, haver dificuldade na orientação da sonda ao meato urinário. Dessa forma, a técnica pode ser repetida algumas vezes até que se obtenha sucesso na cateterização do orifício. Este dado pode contribuir para maior exposição da criança à ocorrência de infecções e traumas.

Outro risco potencial é o enovelamento da sonda na bexiga, por excesso de cateter introduzido. Os familiares relembram que este aspecto da técnica é fundamental: 


\section{Introduzo a sonda até vir a urina. Aí eu paro. (Violeta)}

[...] e introduzo na uretra. Até uns $5 \mathrm{~cm}$, aí tiro um pouquinho, faço um vai e vem, ás vezes tiro e coloco de novo, a mesma sonda. (Lotus)

Boto bem a sonda, eu vou contando, até quando parar a contagem no número 7, aí eu paro de colocar a sonda, aí vou colocando até quando parar no numero 7. (Azaléia)

Observou-se que não há uma orientação única sobre quando parar de introduzir a sonda, demonstrando a necessidade de padronização do procedimento. A literatura mostra que nos dois sexos, se introduz a sonda até que a urina comece a fluir, após isso deve-se segurar a sonda nesse lugar. Alerta que não se deve mover a sonda para dentro e para fora quando encontrar resistência, é preciso pressionar de forma leve, mas firme, até que a sonda avance ${ }^{11}$. Um dos procedimentos utilizados pelos familiares, para a facilitação da drenagem da urina pela sonda, foi o uso da seringa, a fim de aspirar o conteúdo:

Logo no comecinho eu fazia (a retirada da urina) com a seringa, mas aí a enfermeira disse que poderia causar danos nela. Aí parei de fazer. (Violeta)

[...] puxo a urina com a seringa, antigamente eu deixava gotejar, mas demora muito, eu ficava com medo de ficar alguma coisa, ai eu prefiro puxar com a seringa, na seringa de $20 \mathrm{ml}$, puxo com a seringa, descarto, se a seringa estiver fazendo resistência, eu já sei que não tem mais nada, ás vezes tem que dar uma mexidinha também na sonda, para poder ver se tem mais. (Alecrim)

Aspirando-se a urina através da seringa, com a finalidade de agilizar o CIL, o familiar pode causar pequenas lesões na parede interna da bexiga. Isso é ocasionado porque a parede da bexiga encosta no orifício do cateter provocando lesões que facilitam a penetração de bactérias. A insensibilidade de algumas crianças com diagnóstico de mielomeningocele aumenta ainda mais o risco de lesão não percebida ${ }^{15}$.

Após a retirada da sonda, é necessário decidir sobre seu destino, sendo descartada ou preparada para a reutilização. Sobre isso, alguns familiares relataram os cuidados que utilizam para reutilizar a sonda:

A gente recebeu um papel do hospital e, lá, falava que era para pegar água filtrada e ferver, pegar sabão de coco, ou sabão neutro; aí tinha uma solução também, que era 1 litro de água para 1 colher de sopa de água sanitária. Lavava a mão direitinho, cheguei a derreter o sabão, deixei a solução com água pronta, aí eu lavava com água corrente, aí depois com a solução de água e sabão, depois tirava com a água filtrada e fervida e depois eu tirava todo o sabão; á jogava a solução com a água sanitária e deixava lá por uma hora e depois lavava com água filtrada, e aí usava a seringa para dar uma secada. Nós fizemos por umas duas semanas. Aí a gente conseguiu parar de reutilizar. (Magnólia)

[...] e coloco a sonda num pote de margarina. E depois lavo a sonda. Uso a sonda 2 ou 3 vezes. Lavo com de- tergente na seringa, injeto com a seringa dentro da sonda, e depois eu injeto água mineral várias vezes, e depois injeto ar para secar por dentro e depois coloco num pote limpo com álcool. Mais tarde utilizo novamente. (Lotus)

Pode-se verificar nas falas, maneiras distintas para reutilização da sonda. Nesse sentido, recomenda-se iniciar pela lavagem do cateter, externo e internamente, com água e sabão neutro, sendo a limpeza interna com uso de seringa de 10 ou $20 \mathrm{ml}$; enxaguar e secar em um pano limpo ${ }^{16}$. Alguns autores recomendam realizar a lavagem exterior com água e sabão e depois enxaguar o interior com água corrente, secar com toalha limpa e manter em lugar seco, dentro de um recipiente limpo ${ }^{17,18}$. Outros, orientam lavar os cateteres com água e sabão e ferver por 10 minutos $^{19,20}$.

Manter o cateter imerso em solução asséptica, torna-se desnecessário e é uma atitude que deve ser desestimulada aos familiares, pois pode causar irritação da mucosa uretral e prejudicar a flora normal, contribuindo para colonização secundária ${ }^{21}$.

O cateter deve ser lavado com água e sabão, enxaguar, secar e guardar em bolsa adequada ou até mesmo armazenado em papel toalha para o próximo uso ${ }^{22}$. Entretanto, alguns dos familiares relataram não reutilizar os cateteres, por insegurança e/ou medo de infecção:

Não, tentei fazer (a reutilização) mas não deu certo. (Jasmim)

Mas na outra reunião eu aprendi que poderia ferver. Mas não faço! (Alecrim)

A decisão de reutilizar ou não a sonda está mais para fins econômicos do que técnicos, tendo em vista as evidências atuais que permitem a reutilização do cateter de forma limpa. Desse modo, deve-se avaliar o custobenefício junto às famílias, a fim de traçar estratégias para melhor atender às suas necessidades sociais.

\section{Conclusão}

As crianças com bexiga urinária neurogênica têm demandas de cuidados específicos de saúde que exigem uma adaptação da família e da criança. Verificou-se, através deste estudo, que a realização da técnica se dá de forma adequada pela maioria dos familiares. A preocupação dos familiares com aspectos essenciais à realização da técnica foram destacados nas falas, tais como a reunião dos materiais necessários, a organização do local, a higienização da criança e das mãos, o uso de lubrificante, a visualização do meato urinário, a introdução da sonda, os cuidados na drenagem da urina e a reutilização da sonda. Entretanto, foram encontradas inadequações nas técnicas entre certos participantes, no que tange ao uso da massagem abdominal e utilização de seringa para auxílio da drenagem da urina, a utilização de luvas de procedimento e estéril, a introdução da sonda de maneira pouco precisa e o não uso do lubrificante. 
Entre as limitações do estudo, destacam-se o reduzido número de participantes e um único cenário que impedem a generalização dos achados.

Torna-se interessante a produção de um guia e/ ou manual para o familiar, com todas as orientações, de forma clara e de fácil entendimento, para uniformização de condutas.

Como estratégia educativa, também sugere-se a realização de grupos com os profissionais e familiares, para a aproximação dos mesmos e a orientação do procedimento de forma prática, a fim de dirimir dúvidas e medos. Ressalta-se, a necessidade do acompanhamento mais frequente dessas crianças, para avaliação do procedimento e sua adequação à idade e à etapa do desenvolvimento infantil.

\section{REFERÊNCIAS}

1.Cipriano MAB, Fontoura FC, Lélis ALPA, Pinheiro PNC, Cardoso MVLML, Vieira NFC. Revisão integrativa de estudos sobre ações educativas para portadores de bexiga neurogênica. Rev enferm UERJ. 2012; 20: 819-24. [citado em 10 mar 2015]. Disponível em: http://www. facenf.uerj.br/v20nesp2/v20e2a21.pdf

2.Furlan MFFM. Experiência do cateterismo vesical intermitente por crianças e adolescentes portadores de bexiga neurogênica [tese de doutorado]. Ribeirão Preto(SP): Universidade de São Paulo; 2003.

3.Santos ND, Thiengo MA, Moraes JRMM, Pacheco STA, Silva LF. O empoderamento de mães de recémnascidos prematuros no contexto de cuidado hospitalar. Rev enferm UERJ. 2013; 22: 65-70. [citado em $10 \mathrm{mar}$ 2015]. Disponível em: http://www.e-publicacoes.uerj. br/index.php/enfermagemuerj/article/view/11436/8985. 4.Rezende JMMM, Cabral IE. A rede social de crianças com necessidades especiais de saúde na (in) visibilidade do cuidado de enfermagem. Rev Latino-Am Enfermagem. 2010; 20: 282-8. [citado em 18 set. 2014]. Disponível em: http:/ www.scielo.br/scielo.php?script $=$ sci_arttext\&pid $=$ S0104$11692012000200010 \& \operatorname{lng}=\mathrm{en} \& \overline{\mathrm{nrm}}=$ isso.

5.Gaiva MAM, Nevez AQ, Siqueira FMM. O cuidado da criança com espinha bífida pela família no domicílio. Esc Anna Nery. 2009;13:717-25. [citado em 10 jul 2014] Disponível em: http://www.scielo.br/pdf/ean/v13n4/ v13n4a05.pdf.

6.Sociedade Brasileira de Urologia. Projeto Diretriz. Bexiga Neurogênica na Infância. 2006. [citado em 20 set 2014]. Disponível em: http://www.projetodiretrizes. org.br/6_volume/05BexigaNeuroInfan.pdf.

7.Socie $\bar{d}$ ade Brasileira de Urologia. Projeto Diretriz: Bexiga Urinária: cateterismo intermitente. 2008. [citado em 20 set 2014]. Disponível em: http://www.projetodiretrizes.org.br/8_volume/12Bexiga.pdf

8.Costa JN, Silva GA, Carvalho ZMF, Almeida PC. Fatores que interferem na realização do cateterismo vesical intermitente limpo em crianças com mielomeningocele. Journal of Nursing UFPE on line. 2009; 3(4). [citado em 21 set 2014] Disponível em: http://www.openthesis. org/documents/Fatores-interferentes-na-do-cateterismo332088.html.

9.Bruni DS, Strazzieri KC, Gumieiro MN, Giovanazzi R, Sá VG, Faro ACM. Aspectos fisiopatológicos e assistenciais de enfermagem na reabilitação da pessoa com lesão medular. Rev esc enferm. USP. 2004; 38:71-9. [citado em 23 ago 2014]. Disponível em: http://www.scielo.br/ scielo.php?script $=$ sci_arttext\&pid $=$ S0080623420040 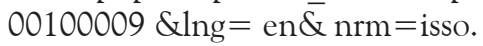

10.Bardin L. Análise de conteúdo. São Paulo: Edições 70; 2011;

11.Sociedade Internacional de Continência da Criança. Guia para criança com cateterismo intermitente limpo. Beverly (USA): ICCS; 2012.

12.Morooka M, Faro ACM. A técnica limpa do autocateterismo vesical intermitente: descrição do procedimento realizado pelos pacientes com lesão medular. Rev esc enferm USP. 2002; 36: 324-31. [citado em 23 ago 2014] Disponível em: http://www.scielo.br/scielo.php?script=sci arttext\&pid $=$ S0080-2342002000400005\&lng $=$ e $n \& \bar{n}$ $\mathrm{rm}=$ isso.

13.Ministério da Saúde (Br). Agência Nacional de Vigilância Sanitária. Pediatria: prevenção e controle de infecção hospitalar: Brasília (DF): ANVISA; 2005. 14.Medicinanet. Bulário Eletrônico. Porto Alegre (RS). 2008. [citado em: 23 ago. 2014]. Disponível em: http://www. medicinanet.com.br/bula/8224/lidocaina_geleia_2.htm.

15.José M. CIL - Detalhes: 4 -Porque não empurrar a urina, nem aspirar com seringa? Minas Gerais. 2012. [citado em 13 out 2014]. Disponível em: http://uroped. blogspot.com.br/2012/11/cil-detalhe-4-de-5-porquenao-empurrar.html.

16.Secretaria Municipal de Saúde de Betim (MG). Normatização de Procedimentos Técnicos no Serviço de Atenção Domiciliar: protocolo do serviço de atenção domiciliar. Betim (MG): Secretaria Municipal de Saúde; 2007.

17.Karolowicz KA, Meredith CE. Adult voiding dysfunction. In: Karolowicz KA. Urologic nursing, principles and pratice. USA: W.B. Saunders; 1995. p.377-407.

18. Rodrigues EAC. Infecções do trato urinário. In: Rodrigues EAC, Mendonça JS, Amarante JMB. Infecções hospitalares: prevenção e controle. São Paulo: Sarvier; 1997. p. 135-48.

19.Azevedo MAJ, Maria MLSS, Soler CMA. Promovendo o auto-cuidado - treinamento e assistência de enfermagem a pacientes portadores de bexiga neurogênica. Rev Bras Enferm.1990; 43(3/4):52-7.

20.Hunt GM, Oakeshott P, Whitaker RH. Intermittent catheterisation: simple, safe and effective but underused. BMJ. 1996; 312(13):103-7. Disponível em: http://www.ncbi.nlm.nih.gov/pmc/articles/ PMC2349752/?page =1 [citado em: 14 out 2014];

21.O'hagan M. Neurogenic bladder dysfunction. 2th ed. (UK): HODH; 1996.

22.I Consenso Brasileiro - Incontinência urinária, Uroneurologia, Disfunções Miccionais. São Paulo: Sociedade Brasileira de Urologia;1999. 